\title{
Çocuklarda Bilgisayar Oyunları Okur-Yazarlığı Örnek Çalışma: \\ "Ghost In The Shell Stand Alone Complex" Oyunu
}

\author{
Yasemin Kilınçarslan* \\ Uşak Üniversitesi, İletişim Fakültesi, Radyo-Televizyon-Sinema Bölümü, Uşak
}

\begin{abstract}
Öz
Görsel okuryazarlı becerilerini kazanma sürecinde dünyaya ilişkin görsel tasarımlar söz konusu olduğunda bir çocuk için "her şey yenidir", ilk kez görülmektedir. Oyun örgüsü içerisinde eylemde bulunan çocuklar, sürekli bir biçimde gözlem halinde olan varlıklar olarak kendilerine yeni bir şeyler sunan dünyayla görsel bir bütünleşme içindedir. Çocuğun izlenimlerinde antimajlar görsel kompozisyonlar olarak süreklilik halindedir ve çocukluğa ait arketipler görsel hafıza bankalarında saklanmaktadır. Fotoğraflar, grafikler, imgeler işlevsel anlamda; teknik ilkeler, kompozisyon, stratejiler, kurgu ve yapım unsurlarıla etkide bulunurken, sosyal ve kültürel anlamda; anlam yaratma, duygu oluşturma, deneysel ve kavramsal bilginin belirlenmesi, bağlantı oluşturma, izleyicileri anlama, görme ve anlama biçimleri, kendi yaşam deneyimlerini kullanabilme ve dünyayı anlamlandırma boyutlarına denk düşmektedir. Bilgisayar oyunları bu süreçte devreye girerek yaratıc ve yenilikçi tasarımlarıyla; yeni öğrenilenleri var olan uygulamalara, yeni kombinasyonlara, yeni görme ve eyleme yollarna aktararak yaratıcllı ve yenilik unsurlarına eklemlemektedir. Çocukların sürekli biçimde bütünleşme içinde olduğu görsel bankalardan olan bilgisayar oyunlar, görsel okuryazarlik becerisini arttıran ve yönlendiren medya içerikleridir. Günümüzde artık oyun tasarımları sadece görmeye ve duymaya değil, hissedebilmeye de ilişkin teknolojik yenilikleri gereklilik olarak öne sürmekte, her bir yeni oyun versiyonu yeni bir katılımo hissiyatına da referansta bulunmaktadır. Bu çalışmada ele alınan ve "Ghost in The Shell" adl animasyonun bir medya uzantısı olarak tasarlanan "Ghost in The Shell Stand Alone" adlı bilgisayar oyunu, görsel ve mekânsal algıyı multiplatform tasarımlar şeklinde ortaya koymakta, mekan-zaman birliğini dağıtarak yapıbozumcu görsel tasarımlarıyla yeni bir teknobilinç oluşturmaktadır. Çalışmada, bilgisayar oyunundan seçilen görsellerin analiziyle, fiziksel tasarımın, statik durumdan canlandırma grafiğe uzanan yolda görüntünün algısal karakteristiğini ne şekilde biçimlediği aktarılacaktır.
\end{abstract}

Anahtar Kelimeler: Görsel Okuryazarlik, Tasarım, Canlandırma, Teknoloji, Dijital Kültür

\section{Computer Games Literacy of Children Case Study: Ghost in the Shell Stand Alone Complex Game}

\begin{abstract}
Everything is new about visual designs of the world and has been seeing for the first time for a child on the process of gaining the visual literacy. Acting children in the game chain are continually in the situation of observation and they have a visual entegration with the world which presents new things. Children's memory-images are continual in their observations as visual compositions and archetypes of their childhood and they are hidden in the visual memory banks. Photographs, graphics, images are effective as functional, technical principles, composition,
\end{abstract}

*Yazışma adresi. Email: yasemink2010@gmail.com 
strategies are effective as fictional In the mean of socio-cultural, creating the meaning, formulating the emotion, defining the experimental as conceptual knowledge, linking the connection, understanding the audiences, seeing and understanding ways are appropriate to self using of life experiments and giving meaning to the world. On this phase, computer games become operational through creative and innovative designs. They transmit the new learning to exist applications, new combinations, new seeing and acting ways thus they articulate the creativeness and innovative elements. Computer games as visusal banks, in which chidren are in a kind of integration, are media contens which lead and enhance their visual literacy. Nowadays, game designs are not only seeing and hearing but for feeling related to technological innovations. Every single new game version has been referring to a new participator feelings. The title of this study as the game of "Ghost in The Shell Stand Alone Complex" is a media extent of animated film "Ghost in The Shell". This game reveals the visual and spatial perception as multiplatform designs, diffuses the time-space unity thus, it creates a new techno-consciousness through deconstructive visual designs. In the study, selected scenes of the computer game will be analyzed and how the physical design formulates the perceptional characteristic of the images will be discussed on the way from static position to animated graphics.

Keywords: Visual Literacy, Design, Animation, Technology, Digital Culture

\section{Gíisiş}

Medya okuryazarlığın amacı çocukların farklı medya içeriklerini okuması analiz etmesi değerlendirmesidir. Medya okuryazarlığı klasik okuryazarlık becerilerinin elektronik medyaya uyarlanması şeklindedir. Bu beceriyi gerçekleştiren çocuklar medya içeriklerindeki şiddet, ayrımcılık, vahşet, önyargı vb. olumsuz kavramlara karşı eleştirel bakış açısını geliştirebilmektedir. Bu noktada medya içeriğinde yer alan görsel imgelerin taşıdığı sembolik anlamlar önem kazanmakta, alg1 ve yorumlama süreçlerine etkide bulunmaktadır. Öte yandan bu sembollerin hangi amaçla kodlandığ 1 ve etkileri de önemli bir husustur.

Bilgisayar oyunlarına yönelik okuryazarlık konusunda ise, günümüzde farklı teoriler geliştirilmektedir. Bunlardan birisi de 'dijital oyunların semiyotik bölgesi' dir. Bu yaklaşım dilbilimsel kavramlara ilişkindir. Bilgisayar oyunları okuryazarlığı medya okuryazarlığına ilişkin olarak da ele alınmaktadır. Bu anlamda medya aracının eleştirel ve analitik kullanımı da söz konusu olmaktadır. Bilgisayar oyunları okuryazarlığı bir çeşit alt medya okuryazarlığı türüdür. (interaktif kitaplar vb.) ve iletişimsel unsurları, sentakslar, estetik boyutları, kültürel sosyal ve ekonomik boyutları önem kazanmaktadır. Bilgisayar oyunları okuryazarlığı; dijital oyunların hayatımızda yaptığı etkilerin farkında olmak, dijital oyunlar aracılığıyla aktarılan mesajların analizi ve eleştirisine ilişkin stratejiler geliştirmek şeklinde tanımlanabilir. Oyunların kültürel ortamda anlayışı ve bakışı ne şekilde etkilediğine bakılırken, oyunlardaki etik ve ahlaki noktalar üzerinde de durulmaktadır.

$\mathrm{Bu}$ niteliklere uygun olarak gerçekleştirilen Omnimax filmler izleyiciye canlı derinlik ilüzyonu verir ve ekran kaybolmuş gibi görünür. Üç boyutlu ilüzyonlarda objeler ekran ve izleyici arasındadır ve farklı objelerin pozisyonları kendi başına tuhaf bir dünya yaratır. Bu bizim dünyamıza benzer olmayan, başka bir dünya, bir rüya dünyasıdır. (Qvortrup, 2002: 255) Bu dünyanın dijital ortamdaki diline hiper metinler 
adı verilir. Bilgisayar oyunları hiper metinler olarak izleyici ve metin arasında yeni bir etkileşim türü olarak karşımıza çıkmaktadır. İnteraktif anlatı türü web tabanlı hiper metindir. Bunun sonucunda ise ortaya hiper kurgu çıkar. Bunlar lineer olmayan diğer metinlerle bağlantı içinde olan bilgisayar ekranındaki metinlerdir. İnternet ortamında sürekli akan ve paylaşılan enformasyona zemin görevi görürler. (bkz. şekil 1.)

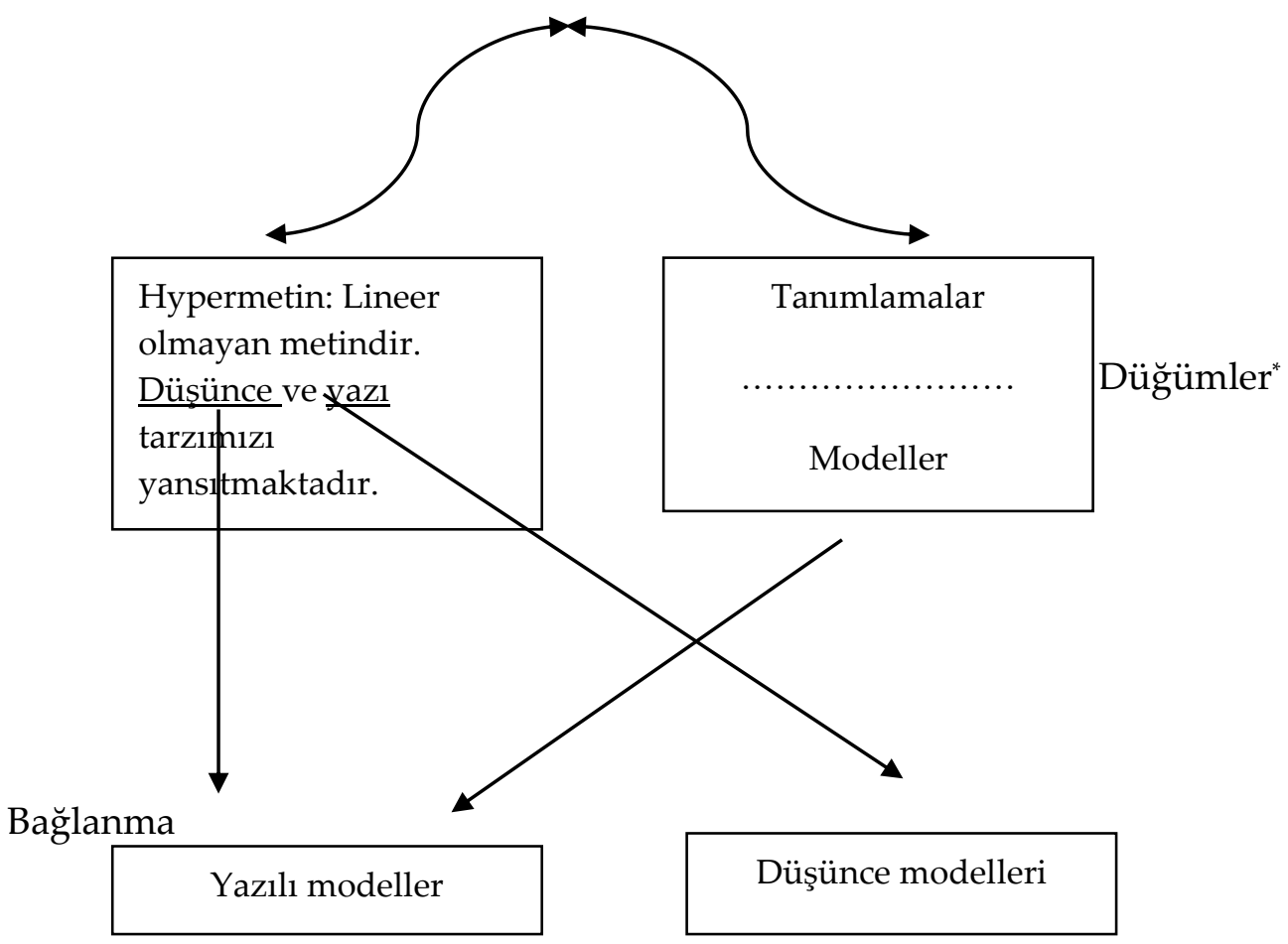

Şekil. 1. Hipermetin Belge Örneği

Kaynak: http://paul.luon.net/hypermedia/chapter1/intro/hypertext.html

Lineer metinler belirli bir giriş, gelişme ve sonuç bölümlerine sahip olan klasik Aristo estetiğine dayanan metinlerdir. Hiper metinlerde ise bağlantılar nonlineer kurgu üzerinde akarak zamansal doğrusallık ortadan kalkar. Simülasyon duygusunun ve aktivasyonun temelini hazırlayan ise bu lineer olmayan akıştır. Bilgisayar oyunlarında hikaye örgüsü başlangıç ve bitiş çizgisi üzerinde farklı aşamalardan tekrar tekrar yaşanarak deneyimlenebilir ya da istenilen noktada bırakmak ya da devam etmek serbestisi vardır. Bu bir anlamda oyuncuya kendi oyun evrenini kurma ve biçimleme imkanı verir. Hiper metinden hiper kurguya giden bu yolda oyuncu tıpkı bir yazar, senarist ya da yönetmen gibi verili uzamda ele geçirdiği patternler üzerinden tekrar tekrar kendi hikayesini kurgular ve kendi oyunculuğunu gerçekleştirir. Bu gerçekleme eylemi esnasında kullanılan yazılı ve görsel düğümler ise dijital oyunların semiyotik bölgesini oluşturmaktadır.

"Düğümler: İçerik metinleri, grafikler, ses, video, diğer veriler. 


\section{1. Çocuklarda Görsel Okuryazarlık ve Bilgisayar Oyunları}

Okuryazarlık becerisinin kazanılabilmesi için uzun yıllardır çocuklara yönelik için farklı teknikler uygulanmaktadır. Test sistemleri çocukların okuryazarlık becerilerini ölçmeye imkan vermekte fakat görsel okuryazarlık söz konusu olduğunda bunun test edilebilir mi yoksa düşünülebilir mi olduğu sorusu ortaya çıkmaktadır. Özellikle İngiliz okul sisteminde medya ve güzel sanatların farklı alanlarında medyanın İngiliz diline, görsel okuryazarlığın ise sanata ilişkin olduğu kabul edilmiştir. Görsel okuryazarlık edebi türde bir okuryazarlık olarak kabul edilememektedir. Dile ilişkin değildir ve bu ayrım kesin bir şekilde yapılmıştır. (Walker ve Chaplin, 1997: 111) Bu yüzden görsel okuryazarlık becerilerinin geliştirilmesi ve etkilerinin analiz edilebilmesi için medya içerikleri önemli bir araç haline gelmektedir.

Görsel okuryazarlık görsel dili kullandığı için ilk başta sözel dile benzemekte, görsel deneyim ve sözel davranış arasındaki ilişki görsel deneyimleme ile son bulmaktadır. Görsel dilden elde edilen deneyimlerin sözel davranışlara ne şeklide yansıdığının ortaya çıkarılabilmesi için bunların uzunluğunun ve yapısal durumun analizi gerekmektedir. (Longhurst, 1974: 104) Algllama, iletişim ve sanat görsel okuryazarlık olgusuna kuramsal bir çerçeve çizmek için yeterli olmaktadır. Bu teoriler kapsamında ele alınacak olursa; sanatı eğlence, yorumlama, geliştirme, güdülenme ve tanımlama anlamında medeni insan olma deneyiminin bir parçası olarak gören görsel okuryazarlık bir sanat disiplinidir. Resim, hareket ve obje sözel olmayan dile ilişkindir. İletişimsel ve meta-iletişimsel becerileri kazanmada önemlidir. (Moore ve Dwyer, 1994:9) Dil sanatı; okuma, anlama, dinleme ve yazmaya ilişkin olunca görsel okuryazarlık da tartışılır hale gelmekte, diğer dil sanatları gibi insan olmanın temel unsurlarından birisi olarak karşımıza çıkmaktadır. Görsel okuryazarlığı oluşturan imgelerin şekilleri, renkleri, metinleri, hareketleri, biçimleri, hatları, boyutları önem kazanmaktadır. Bu durum görsel düşünme, görsel zeka, görsel farkındalık, görsel duyarlılık ve görsel sanatlara dair bilinçli bir okuma işlemini kapsamaktadır. Çocuk, imgelerle dünya algısını nasıl oluşturacağını ve görsel medya içeriklerine ilişkin nasıl bir görüş belirleyeceğini saptamaktadır. Böylelikle görsel olarak neyi anladığını belgelemiş olmakta ve görsel bir filmi oluşturmaktadır (Machado, 2010-2007:165-166).

Sürekli olarak teknoloji tabanlı uygulamaların günlük hayatımızdaki beklentilere denk düşmesini beklemekteyiz. Beklentilerimize ilişkin bu uygulamaların bir mecrasını da popüler interaktif bilgisayar donanımları ve video oyunları oluşturmaktadır. Çağımızda artık enformasyon olgusu kendisiyle oynanmasını istemektedir ve bu yüzden insanlar ekrandaki verilerle bütünleşik hale gelmiş durumdadır. Tasarımların semiyotik ve gramatik görünümleri kültürel yapıyı ortaya koyucudur ve oyun dizaynını yazma becerileriyle koşuttur. (Burn, 2009:114) Kişisel ve sosyal gelişim, motivasyon, dikkat ve grup çalışması, dil ve okuryazarlık, dinleme becerisi, organizasyon beceri ve iknası, sekanssal ve net düşünce, matematiksel beceriler, yaratıcllı, motor kontrol sisteminin gelişmesi, dünyayı anlama ve yorumlama becerileri bilgisayar oyunlarının olumlu etkilerindendir (Larson ve Marsh, 2005:77). Oyun okuryazarlığı ise hangi tür oyunların ne şekilde işlediği ve etkileri ile 
ilgilidir. Belirli zaman ve uzamda işleyen amaçsal bir sistemdir. Bu noktada oyuna verilen anlamlandırma önemlidir. Tasarımsal süreçler oyuncunun tasarım olgusunu kavrayıp anlamlandırmasıyla öğrenme sürecinde farklılaşmış etkilere neden olmakta, oyunun bakış açısından dünyanın nasıl göründüğü önem kazanmaktadır. Oyun bir tür spesifik anlamlandırma yaratma aracıdır ve oyunun sistemi, oyuna ve tasarıma dayanmaktadır.

\section{Mekan Tasarımları ve Sanal Platformun Anlatımı Dönüştürücü Etkisi}

Tele-varoluş sanal gerçekliğin bir uzantısıdır. Kamera, mikrofon, vb. uzantılar hissedilir anlamda güçlü bir geri besleme sağlamakta, uzaktan kumandayla yönlendirilebilen diğer dijital aygıtlar aracılığıyla kullanıcı neyi deneyimleyeceğine istediği mekanda var olarak karar verebilmektedir. Bu anlamda, sanal gerçeklik tabanlı grafik kullanımı söz konusu olduğunda metin merkezli durum ağ merkezli duruma dönüşmektedir. Sanal gerçekliğin en uygun deneyimlenebileceği mecra olan bilgisayar oyunlarında ise motivasyonun sağlanması objenin çok daha yakından incelenebilmesi mümkün hale gelmektedir. Oyunlarda sanal çevre bağlamında sanal interaktif iletişim kullanılmaktadır. Dikkati çekici bu durum motivasyonu arttırıcı hale getirerek okuryazarlık becerilerini de arttırmaktadır. Görsel efektler ve oyun modellerinin kullanımı imajinasyonu arttırmakta ve öğrenmeyi hılandırmaktadır. Yapılan çalışmalar 3D sanal çevre tabanlı tasarımlarla öğretilenlerin klasik öğrenme sürecine göre daha fazla akılda kaldığını saptamıştır.

Farklı sanat dallarıyla bütünleşik olarak yorumlanabilecek olan bilgisayar oyunları temelini, yazın, resim, mimari tasarım ve müzikten almaktadır. Bilgisayar oyunları, eski medyanın semiyotik sistemini dönüştürmekte, değiştirmekte ve diğer alt medya türü olan sinemayla yakın ilişki içinde olmaktadır. Yeni bir medya içeriği olarak görülmekte ama melez özellikler göstermektedir (Lowood ve Nitsche, 2011:261262). Mimari tasarımda bilgisayar oyunları konusunda ise; oyun endüstrisinin teknolojik ve sanatsal gelişimi militer endüstriyel gelişimle orantılıdır. Bu durum sanal gerçeklik merkezli olarak gerçekleşmektedir. A $\breve{g}$ üzerindeki toplulukların katkılarıyla gelişim hızlı ve paylaşılır hale gelmekte, internet üzerinde fiziksel mevcudiyetler çoklu kullanıcılar ile etkileşim içine girmektedir. (Smith ve Salvendy, 2001:579) Yeni jenerasyon oyun modelleri için yeni mimari tasarımlar önemli bir uygulama haline gelmektedir. Böylelikle gerçek zamanlı mimari tasarımlar, sanal gerçeklik görselleştirmesini malzemelerin gerçeklik hissiyatını arttırarak sağlamaktadır. İzleyici gerçek hayatta nasıl olması gerektiği gibi bir hissiyata sahip hale getirilmektedir (Dong vd., 2007:2007). Bu anlamda mimari dizayn ve yapılandırma sanal gerçeklik yaratımının en önemli unsurudur. Günümüzde kişisel amatör bilgisayarlarda bile donanım teknolojisi yüksek kalitede görseller üzerine çalışmaktadır. Özellikle üç boyutlu sanal çevre uygulamaları son derece ucuz ve kolay yoldan ulaşılabilir hale gelmiştir. Aynı zamanda birçok kişi tarafından paylaşılabilen sanal çevre tasarım uygulamaları mevcuttur. Sistem ve animasyon mühendisliği bunları sağlayan kollardır (Jacko ve Stephanidis, 2003:1011). 
Bilgisayar oyunlarının bir diğer özelliği ise simülasyon olgusudur. Bilgisayar oyunları bir nevi simülasyon tasarımları olarak kullanıcıların interaktif yapılı eğlence içinde olduğu bir mecradır. Sistemde, kullanıcı ara yüzü, belirli bir mantık ve bir veri tabanı mevcuttur. Simülasyonun kullanıcı ara yüzünün bileşeni yeterli ve yetkinse iyi bir oyun süreci yaşanmaktadır. Grafik tasarımın kendisi ise birebir kullanıcı ara yüzüne referans olmaktadır. Oyunun veri tabanıyla ve mantığıyla iletişim içinde olmak, mantıksal ve verisel olarak oyuncunun eylemlerine geri beslemede bulunur. Oyundaki eylemler belirli bir mantığa göre harekete geçer ve içinde dolandığı çevre sanal ortam olarak tanımlanır. Kullanıcı ara yüzü ise bilgiyi oyuncudan oyuncuya taşır (Laramée, 2002:163-164). Simülasyonun eşlik eden kavramı olarak Sanal gerçeklik ise, kullanıcıların sadece yönlendirici olarak değil elektronik ortamda katılımcı olmasına izin vererek, interaktif boyutta ortaya çıkan bilgisayar grafik ortamıdır. Bilgisayar ortamında üç boyutla yapılabilen tüm tasarımları kapsamaktadır. Bu interaktif ortam, yapıların alanlarını keşfetmeyi, objelere dokunmayı, kapıları açmayı sağlar. Sanal gerçeklik; modelleme diliyle, sanal gerçeklik ekranının ve mouse'un kullanımıyla interaktif olarak tasarımın içinde hareket edilebilir. Sanal gerçeklik teknolojisi sadece interaktif değil içe alıcıdır. Kullanıcının görüntü alanı kaplanır, objelere dokunulabilir ve bu sanal bir ekran içinde gerçekleşir (Salvan, 2000:930). Üç boyutlu sanal gerçeklik platformları farklı objelerle oynamak ve farklı deneyimlere yaşamak için role-playing ile desteklenmektedir. Role-playing'de oyuncular belirli karakterleri seçer, yaratıcı ve entellektüel anlamda, duygusal ortaklaşa kurgu ile hikayeyi yaratır ve yönlendirirler. Böylece ortam görsel bir tiyatro haline döner. Çok kullanıcılı sanal ortamlar ise, çoklu sanal gerçeklik ortamında kullanıcı yaratımına dayanan oyunlardır. Anlatım yaratılmaz fakat platformlar kullanıcıyı destekler.

\section{Dijital Oyunların Semiyotik Bölgesi ve Ghost in The Shell Stand Alone Complex Bilgisayar Oyunu}

Bilgisayar oyunlarına ilişkin kuramsal bir yaklaşım sözkonusu olduğunda yapısalcı anlatısal teori kapsamında simülasyon aşaması, performans aşaması ve söylem aşaması belirlenmektedir. Simülasyon oyunlarının semiyotik bölgesi ise; performans, simülasyon ve söylem aşamasından meydana gelmektedir. Bu noktada, oyun unsurları, tasarım, etkileşim ve oyuncu etkilerine ilişkin karşılıklı bir bağlantı sözkonusu olmaktadır (bkz. şekil 2.). 


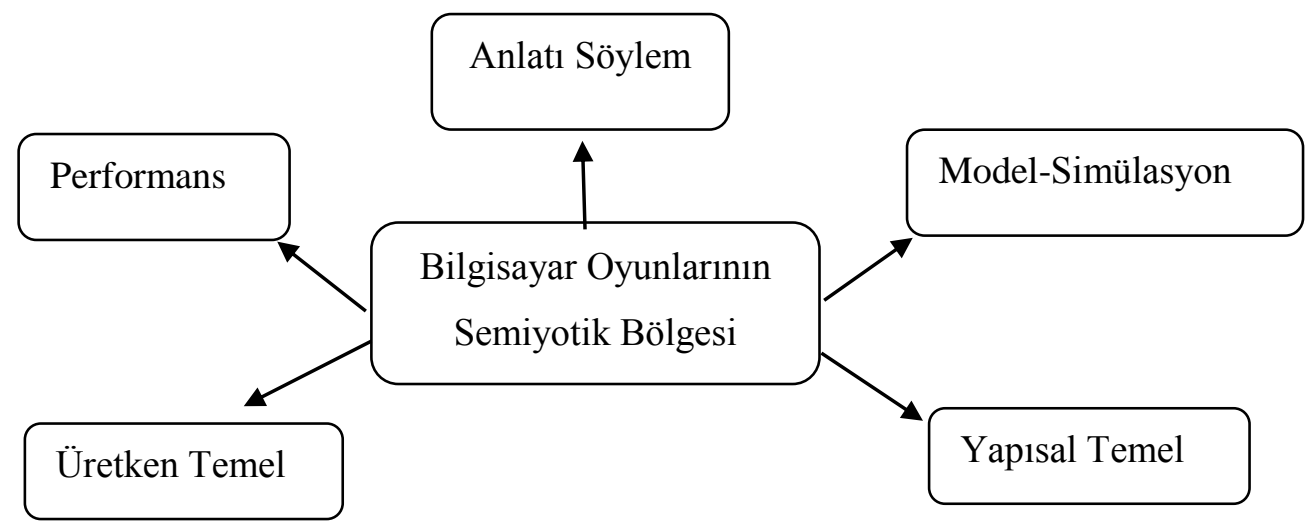

Şekil. 2. Bilgisayar Oyunlarının Semiyotik Bölgesi

Kaynak: http://www.gamestudies.org/0501/lindley/

Semiyolojik açıdan bilgisayar oyunlarına bakıldığında sosyal kodlar; oyuncunun oyun oynama esnasında diğer oyuncularla etkileşimi içine girişi, bedensel teması, fiziksel oryantasyonu, yüz ifadeleri, mimikleri ve duruşudur. Davranışsal kodları ise role playing oluşturmaktadır. Tür, retorik ve stilistik kodlar; oyunun anlatısı, karakterleri, aksiyon ve diyalog'dur. Yorumlayıcı kodlar anlamında; görsel algılamaya denk düşenler algısal kodlar, oyunun söylemini barındıran yapı ise ideolojik kodlardır. Tüm kodların bileşimi bir atom parçasına benzetebileceğimiz bilgisayar oyunlarının semiyotik bölgesinin nötronlarını ve protonlarını oluşturmaktadır. Merkezin etrafını çeviren tüm temeller ya da yapılar içerilerinde bu kodları barındırmaktadır. Buna göre Ghost in the Shell: Stand Alone Complex adlı bilgisayar oyununun semiyotik bölgesi saptanan görsellere dayalı olarak aşağıda sözü edilen tarzda çözümlenebilir.

\section{Oyunun Künyesi}

Oyunun Adı: Ghost in the Shell: Stand Alone Complex

Tasarımcı Firma: Sony Computer Entertainment Inc.

Konu: Tamamen dijitalleşmiş, robotların ve androidlerin insan ırkıyla bir arada yaşadığı bir toplumda, ülkeyi ve kamu güvenliğini tehdit edenleri ve zarar verenleri ortadan kaldırmak.
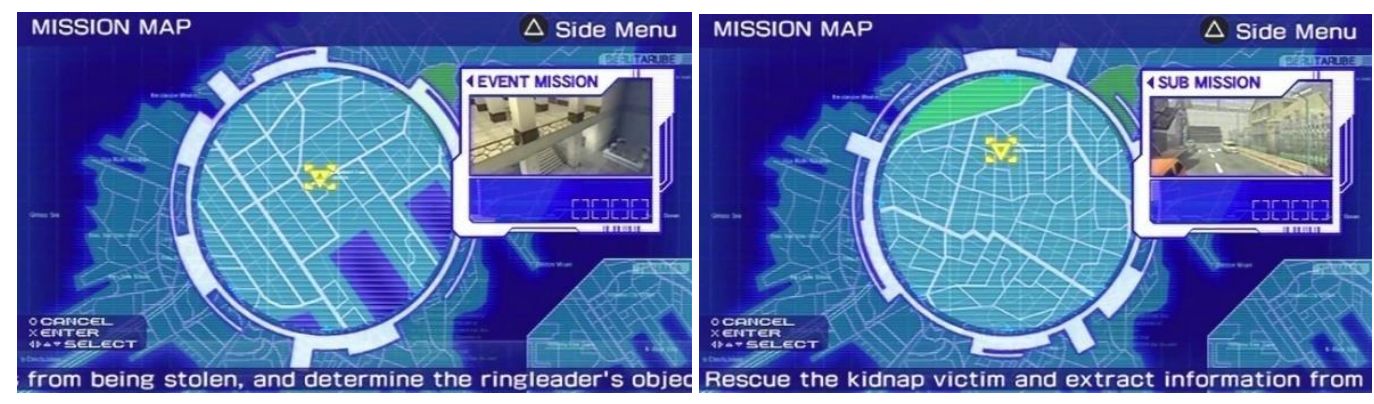

Resim 1. Görev Haritaları 
Siberpunk nitelikli anime türün uzantısı olan bu oyunda, görev haritaları olayların gelişim zeminini, plotun gerçekleşme yerini belirtmektedir. Bu yüzden fiziksel hareket alanı tanımlanmaktadır. Birinci görev haritasında belirlenen mekanlar rehineleri kurtarmak, belgelerin çalınmasını engellemek ve terörist elebaşlarının amaçlarını saptamak üzere kullanılmaktadır. İkinci görev haritasında ise kaçırılan kurbanı kurtarmak ve çılgın androidden bilgileri söküp çıkarmak için bulunulacak bölgeler saptanmıştır. Bu aşama, oyunun fiziksel uzamını oluşturmak ve performans alanlarını ortaya koymak için tasarlanmıştır. Bu şekilde oyunculara hedef noktalar ve hareket alanları hakkında önceden bilgi verilerek bu alanların dışında bir arayışta olmaları engellenmekte, görev haritaları hareket sınırlarının çizilmesi için kullanılmaktadır. Bu haritalarla mekan hissiyeti oluşturulmaya çalışılır ve olaylara odaklanma hızlandirılır.

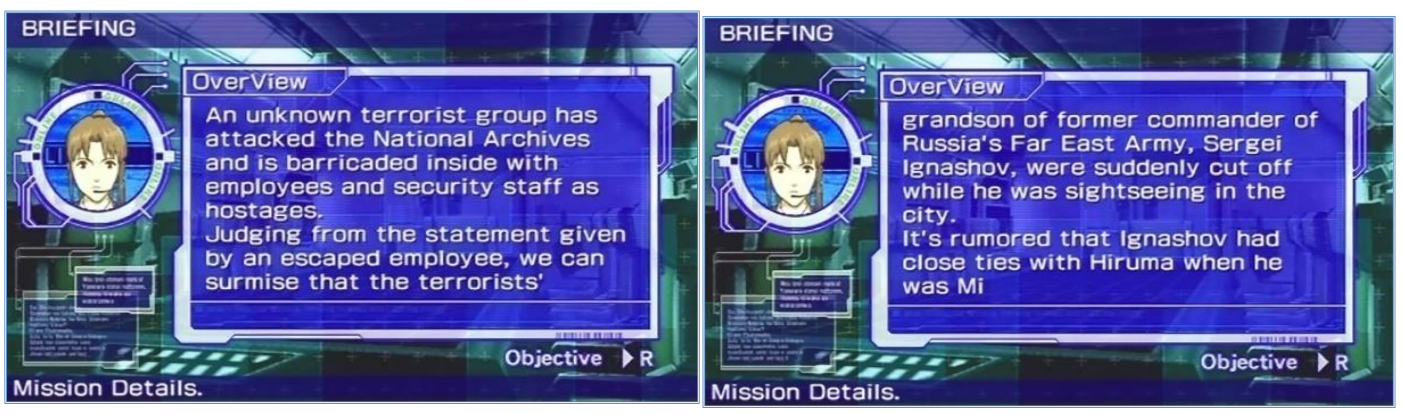

Resim 2. Göreve İlişkin Ayrıntılı Bilgi

Oyunun ne konuya dair olduğunun ve detaylı açıklamasının yapıldığı genel görünüm sahnesinde oyunun hakim söylemi de ortaya çıkmaktadır. Militer, agresif, yok edici, tehditkar, korumacı, milliyetçi unsurların baskın söylemi altında birinci aşamada; kimliği belirsiz teröristler ulusal arşive saldırmış, çalışanları ve güvenlik görevlilerini içeride rehin almışlardır. H-88 adlı belgeyi ele geçirmeye çalışan teröristler aynı zamanda binanın belirli bölgelerini de kontrol altında tutmaktadır. İkinci aşamada ise; Rusya'nın eski Uzakdoğu ordusunun komutanı Sergei Ignashov'un torunuyla olan bağlantı şehir turu esnasında kaybedilmiştir. Bu eylem Hiruma'ya karşı suikast düzenleyen terörist grupların işi gibi görünmektedir. Bu bilgi şehrin $\mathrm{N}$-sisteminden elde edilmiştir. Suçlunun çocuğa eşlik eden kontrolden çıkmış bir android olduğu sanılmaktadır. Olayın basit bir suç mu yoksa dışarıdan hacker müdahalesiyle gerçekleşen bir arıza olayı mı olup olmadığı bilinmemektedir. Androidin içindeki bilgiler olayın çözümlenmesinde gerekli olduğu için androide zarar verilmeden ele geçirilmesi gerekmektedir. Her iki enformasyon aktarımında da kimliği belirsiz düşmanlar, terörist olarak kabul edilen kişiler, ya da bu kişilerce yönlendirilen bir androidin varlığı mevcuttur. Oyunda performans gösterecek olan oyuncular için bu denli detaylı bir bilgi sistemi çok gerekli olmasa bile güdüleme açısından güçlendirici olabileceği düşünüldüğü için detaylandırılmıştır. Böylelikle görev haritasında fiziksel mekanın sınırlarının çizilişi gibi göreve ilişkin ayrıntılı bilgi aşamasında da zihinsel kavram haritalarının sınırı çizilmektedir. Oyuncu aktivasyonunu belirli bir mantığa ve amaca dayandırmaktadır. 

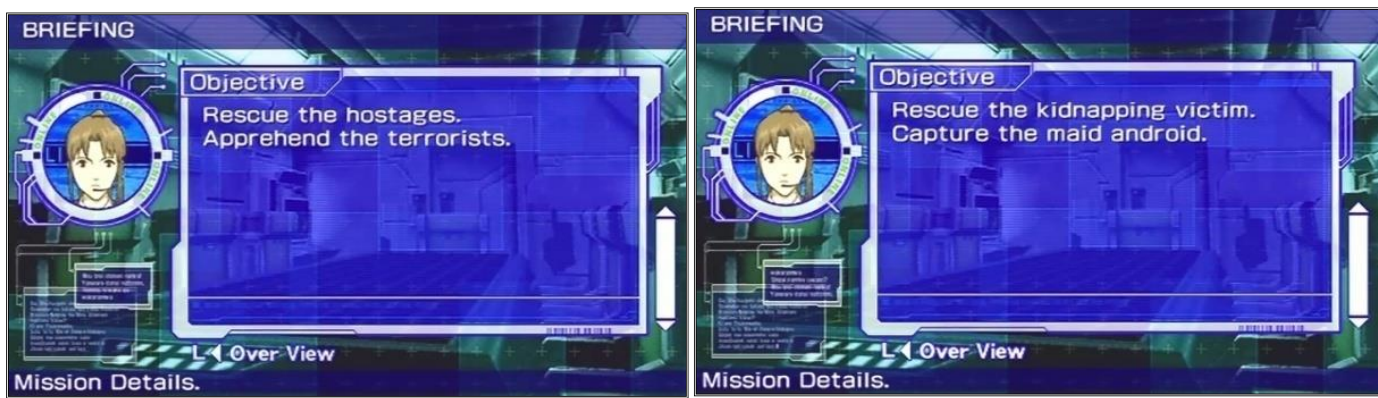

Resim 3. Görevin Amaçları

Oyunda enformasyon aktarımı sahnesiyle belirli bir söylem oluşturulmakta, bu söylem amacın belirlenmesi ile güçlendirilmektedir. Bu noktada komuta-emir zinciri devreye girmekte ve direkt mesaj verilmektedir. "-Rehineleri kurtar, teröristleri tutukla, kaçırılan kurbanı kurtar, androidi yakalayarak etkisiz hale getir." Bu şekilde oyuncu yetkili bir kaynaktan gelen görevi kendi üzerine atayarak göreve hazır gelmektedir. Kendi kendine oyuna müdahil olunmasının yerine bu şekilde verilen emirlerle daha net olan ve performansı etkileyici bir özdeşleşme yaşamaktadır.
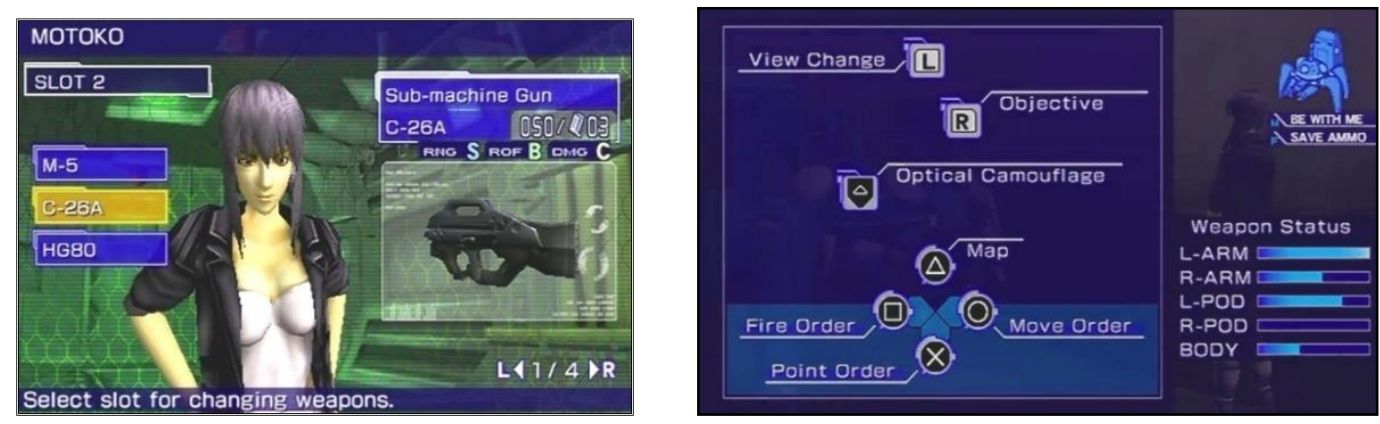

Resim 4. Göreve Atanan Karakter-Seçilen Silahlar-Strateji Belirleme

Resim dörtte görülen performans aşamasında, özel olarak eğitilmiş bireylerden meydan gelen karakterlerin seçimiyle aktif hale gelen oyuncular, belirli bir çatışma stratejisi belirleyerek oyunun biçimlenmesine ve değişmesine neden olmakta, karakterlerin kullanacağı silahlar farklı seçenekler arasından belirlenmekte, her silahın yıkıcı, öldürücü, yok edici özellikleri gösterilmekte, tıpkı savaş alanındaymış gibi manevralar belirlenerek uzamsal dönüşler yaratılmaktadır. Böylelikle sanal dünyanın yaratımı ve deneyimlenmesiyle simülasyon aşamasına geçilmektedir.

\section{Sonuç ve Tartışma}

Bilgisayarda oyun mekaniğiyle yaşamsal deneyimleme alanı belirlenmekte, böylelikle hayat içinde ufak hayatlar yaratılabilmektedir. Duyguların işlenimi ve aktarımı verili hikaye ile oluşmaktadır. Grup aidiyeti ve kolektivist eylemler çok oyunculu seçenekle sağlanmaktadır. Bunun sonucunda ise bilgisayar oyunlarının öğrenimi ve buradaki dilin çözümlenmesi yeni bir edebi türü oluşturmakta, edebiyat, dil ve oyun arasında bir ilişki kurulmaktadır. Yeni çalışmalara yol gösterecek olan soru; bu türün edebi türün bir alt türü mü olduğu, yoksa başlı başına estetik bir öznelliğe mi sahip olduğudur. Oyuncular açısından bakıldığında bilgisayar oyunlarına 
ilişkin yapılan araştırmalara göre; oyuncuların yüzde kırkı kadın yüzde altmışı ise erkek olarak belirlenmiştir. Baskın olan erkek kullanıcılara hızla yetişmekte olan bir kadın oyuncu profili ortaya çıkmaya başlamıştır. Oyun süreleri kısaltılmış tek ya da iki oyuncu yerine çok oyuncu seçeneği getirilmeye başlanmıştır. Oyuncuların yarıdan fazlası tek başlarına değil diğer oyuncularla birlikte oynamaktadır. Bu durumun nedeni oyunların yüzde yetmişinin online olarak oynanmasıdır. Üretken temel, hikayeden, haritalardan, aşamalardan, nesnelerden ve modellerden oluşmaktadır. Bu yeni makine çağının yeni estetik deneyimi bilgisayar ekranında gerçek yaşam deneyimine dönüşmektedir. Dijital çevre, düşünme ve bilgi işleme sürecini değiştirmiş, dijital bir dil ortaya çıkmıştır. Bu durum ise görsel enformasyon arzusunu ve sunumunu hizlandırmaktadır. Biçimsel ve yapısal olarak oyunun metni oyuncunun oyun deneyimlerini etkilemektedir. İnsan zihni ve bilgisayar uzantılar arasında bir etkileşim ortaya çıkmaktadır. Zihnin fiziksel dinamikleri metnin ve oyunun yaratıcı deneyimlenmesiyle bağlantılanmaktadır. Böylelikle sembolik sunumlar gerçekliğin fiziksel içeriğinin yerini almaktadır.

\section{Kaynakça}

Brunnett, Guido Coquillart, Sabine ve Welch, Greg (2011). Virtual Realities: Dagstuhl Seminar 2008. Wien: Springer Verlag

Burn, Andrew (2009). Making New Media: Creative Production and Digital Literacies. New York: Peter Lang Publishing Inc.

Dong, Andy Moere, Andrew Vande ve Gero, John S (2007). Computer-Aided Architectural Design Futures 2007, Proceedings of the 12th International CAAD Futures Conference. Netherland: Springer Verlag.

Jacko, Julia A ve Stephanidis, Constantine (2003). Human-Computer Interaction: Theory and Practice Part I. New Jersey: Lawrence Erlbaum Associates Inc.

Laramée, Francois Dominic (2002). Game Design Perspectives. Massachusetts: Charles River Media Inc.

Larson, Joanne ve Marsh, Jackie (2005). Making Literacy Real: Theories and Practices for Learning and Teaching. London: Sage Publications.

Longhurst, Thomas M (1974). Linguistic Analysis of Children's Speech: Readings, MSS Information Corporation.

Lowood, Henry E ve Nitsche, Michael (2011). The Machinima Reader. USA:MIT.

Machado, Jeanne M (2010-2007). Early Childhood Experiences in Language Arts: Early Literacy. USA: Wadsworth Cengage Learning

Moore, David Mike ve Dwyer, F M (1994). Visual Literacy: A Spectrum of Visual Learning. New Jersey: Educational Technology Publications.

Qvortrup, Lars (2002). Virtual Space: Spatiality in Virtual Inhabited 3D Worlds, London: Springer Verlag.

Salvan, George Salinda (2000). Architectural and Construction Data: A Digested Book for Daily Use. Ouezon City: JMC Press Inc. 
Smith, Michael J ve Saivendy, G (2001). Usability Evaluation and Interface Design: Cognitive Engineering, Intelligent Agents, and Virtual Reality, Volume 1. New Jersey: Lawrence Erlbaum Associates Inc.

Walker, John A ve Chaplin, Sarah (1997). Visual Culture: An Introduction, New York: Manchester University Press.

Wolf, Mark J P ve Perron, Bernard (2003). Video Game Theory Reader Two, New York: Routledge

http://paul.luon.net/hypermedia/chapter1/intro/hypertext.html. 11.04.2013.

http://www.gamestudies.org/0501/lindley. 11.04.2013 